\title{
An Intermediate Frequency Amplifier for High-Temperature Applications
}

\author{
Muhammad Waqar Hussain, Hossein Elahipanah, Stephan Schröder, Saul Rodriguez, Member, IEEE, Bengt \\ Gunnar Malm, Senior Member, IEEE, Mikael Östling, Fellow, IEEE and Ana Rusu, Member, IEEE
}

\begin{abstract}
This paper presents a two-stage small signal intermediate frequency (IF) amplifier for high-temperature communication systems. The proposed amplifier is implemented using in-house silicon carbide ( $\mathrm{SiC}$ ) bipolar technology. Measurements show that the proposed amplifier can operate from room temperature up to $251^{\circ} \mathrm{C}$. At a center frequency of $54.6 \mathrm{MHz}$, the amplifier has a gain of $22 \mathrm{~dB}$ at room temperature which decreases gradually to $16 \mathrm{~dB}$ at $251{ }^{\circ} \mathrm{C}$. Throughout the measured temperature range, it achieves an input and output return loss of less than $-7 \mathrm{~dB}$ and $-11 \mathrm{~dB}$, respectively. The amplifier has a 1-dB output compression point of about $1.4 \mathrm{dBm}$, which remains fairly constant with temperature. Each amplifier stage is biased with a collector current of $10 \mathrm{~mA}$ and a base-collector voltage of $3 \mathrm{~V}$. Under the aforementioned biasing, the maximum power dissipation of the amplifier is $221 \mathrm{~mW}$.
\end{abstract}

Index Terms-4H-SiC BJTs, high-temperature, IF amplifiers, matching networks.

\section{INTRODUCTION}

Communication systems at high-temperatures are desired for applications such as aviation [1], deep oil well drilling [2], future space exploration missions [3] and combustion engines. For these applications, the use of conventional semiconductors like silicon is fundamentally limited by its maximum operating temperature e.g. $225{ }^{\circ} \mathrm{C}$ for SOI technology [4]. Therefore, wide bandgap materials like silicon carbide ( $\mathrm{SiC}$ ) and gallium nitride $(\mathrm{GaN})$ are gaining particular interest as they can operate reliably at much higher temperatures [5].

Between the two aforementioned wide bandgap semiconductors, GaN has generally remained the focus of hightemperature, high-frequency circuits for communication systems. In that regard, a number of high-temperature amplifiers, ranging from power amplifiers (PAs), low noise amplifiers (LNAs) to intermediate frequency amplifiers have been demonstrated using $\mathrm{GaN}$ high electron mobility transistors (HEMTs). For example, a class-E PA has been demonstrated to operate reliably up to $150{ }^{\circ} \mathrm{C}$ using AlGaN/GaN HEMT [6]. Operation of a AlGaN/GaN based PA has been demonstrated at $200{ }^{\circ} \mathrm{C}$ in [7]. Early works also demonstrated successful operation of a wideband LNA up to $230{ }^{\circ} \mathrm{C}$ using commercial GaN/SiC HEMTs [8]. Utilizing the same technology, an IF variable gain amplifier with a center frequency of $97.5 \mathrm{MHz}$ has been shown to work from $25^{\circ} \mathrm{C}$ up to $230{ }^{\circ} \mathrm{C}$ [9].

The maximum operating temperature of amplifiers $\left(230^{\circ} \mathrm{C}\right)$ in [8], [9] is governed by the rated junction temperature of

The authors are with the KTH Royal Institute of Technology, Stockholm, Sweden (e-mail: mwhus@kth.se; hosseine@kth.se; stephan.schroder@ee.kth.se; saul@kth.se; gunta@kth.se; mostling@kth.se; arusu@kth.se). their constituent GaN/SiC HEMTs. This maximum operating temperature can be extended, in theory, to $500{ }^{\circ} \mathrm{C}$ by using our in-house developed $4 \mathrm{H}-\mathrm{SiC}$ bipolar junction transistors (BJTs) [10]. However, the temperature ratings of currently available commercial passives, especially capacitors, limits the maximum operating temperature to around $250{ }^{\circ} \mathrm{C}$.

Due to the relatively modest power gain of the current inhouse SiC BJTs at high-temperature and high-frequencies, we envision receiver topologies where the majority of the receiver gain is provided at intermediate frequencies after down-converting the input signal. In that regard, we present a two-stage small signal IF amplifier for high-temperature communication receivers. The proposed amplifier is based on $4 \mathrm{H}-$ $\mathrm{SiC}$ bipolar technology and is shown to operate successfully from room temperature up to $251{ }^{\circ} \mathrm{C}$.

The paper is organized as follows. Section II presents the fabrication and characterization of $\mathrm{SiC}$ BJTs used to design the proposed IF amplifier. Section III describes the circuit design. Section IV shows the measurement results at various temperatures. The conclusions are drawn in Section V.

\section{DEVICE FABRICATION AND CHARACTERIZATION}

The active devices used in the proposed IF amplifier are in-house $4 \mathrm{H}-\mathrm{SiC}$ BJTs. The fabrication process and electrical characterization of the BJTs are described in this section.

\section{A. Device Fabrication}

The BJTs were fabricated on a 4 -inch, $4^{\circ}$ off-axis $4 \mathrm{H}-$ $\mathrm{SiC} \mathrm{n}^{+}$substrate with six epi-layers. The BJTs used in this work have two emitter fingers with a finger length and width of $40 \mu \mathrm{m}$ and $10 \mu \mathrm{m}$, respectively. Fig. 1 shows the cross-sectional view of a single finger structure along-with the nominal thickness and doping concentration of each of the six epi-layers. Reactive ion etching (RIE) was utilized to structure the emitter, base and collector layers. The final collector mesa to the p-isolation layer was formed to separate the on-wafer devices from each other. The etching uniformity of $\pm 7 \%$ was achieved by controlled SiC dry etching [11], [12]. Improving the surface morphology after dry etching and surface passivation minimizes the surface recombination and significantly increase the current gain. A dry sacrificial oxidation was grown in $\mathrm{O}_{2}$ for 1 hour to smoothen the surface after the etching steps. Next, a $40 \mathrm{~nm}$ thick $\mathrm{SiO}_{2}$ was deposited using low-temperature PECVD and annealed at $1250{ }^{\circ} \mathrm{C}$ in $\mathrm{N}_{2} \mathrm{O}$ for 1 hour to form passivation layer [13]. 


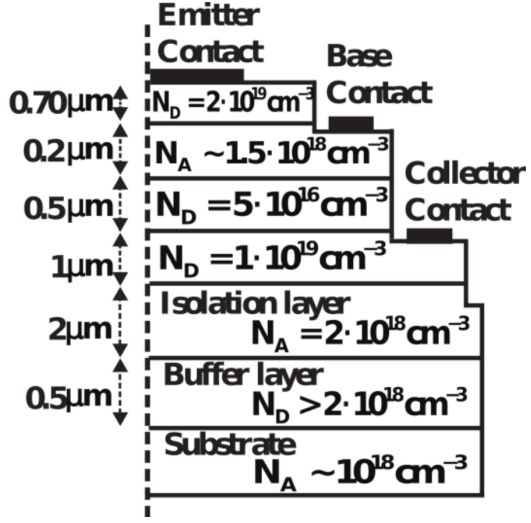

Fig. 1. Cross-sectional view of the epi-layers.
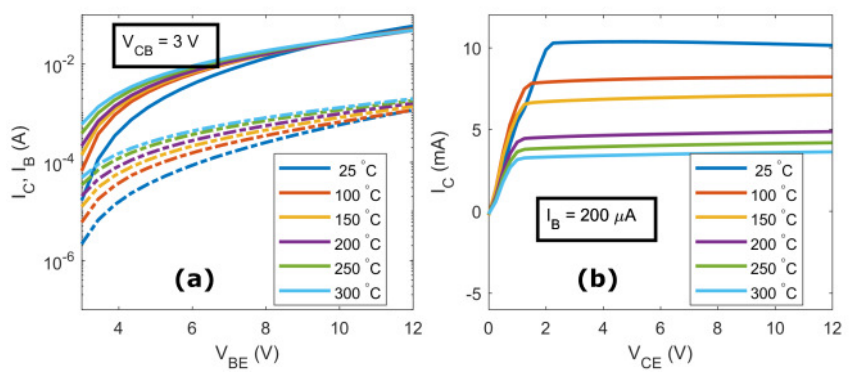

Fig. 2. Measured IV characteristics from $25^{\circ} \mathrm{C}$ to $300{ }^{\circ} \mathrm{C}$ (a) $\mathrm{I}_{\mathrm{C}}$ (solid) and $\mathrm{I}_{\mathrm{B}}$ (dashed) as a function of $V_{B E}$ (b) output characteristics at $\mathrm{I}_{\mathrm{B}}=200 \mu \mathrm{A}$.

Around $100 \mathrm{~nm}$ thick layer of $\mathrm{Ni}$ was deposited and patterned on the emitter and collector. The wafer was annealed at $950{ }^{\circ} \mathrm{C}$ for $1 \mathrm{~min}$. to form the ohmic n-contacts. A $110 \mathrm{~nm}$ metal stack layer of $\mathrm{Ni} / \mathrm{Ti} / \mathrm{Al}$ with a ratio of $10 / 15 / 85$ was patterned on the base and annealed at $820{ }^{\circ} \mathrm{C}$ for 2 mins. to form the p-contacts. A contact resistivity of $5 \times 10^{-6} \Omega \cdot \mathrm{cm}^{2}$ and $8 \times 10^{-4} \Omega \cdot \mathrm{cm}^{2}$ for the $\mathrm{n}$ - and $\mathrm{p}$ - ohmic contacts was achieved, respectively. A PECVD oxide layer with a thickness of $1 \mu \mathrm{m}$ was deposited. The oxide openings to the metal contacts were formed by dry etching. A $500 \mathrm{~nm} \mathrm{Ti} / \mathrm{TiW} / \mathrm{Al}$ metallization was sputtered and patterned to form the first interconnection layer. Subsequently, to form the second interconnection metal layer, a $1 \mu \mathrm{m}$ PECVD oxide was deposited as the insulator layer and the contact windows were opened. Finally, $1 \mu \mathrm{m}$ Ti/TiW/Al metallization layer was sputtered to make metal pads. In previous work [10], we have shown that electro-migration becomes a dominant failure mode, limiting the operation time to a few hours at high-temperature. That motivates using a dedicated high-temperature metallization [14], [15]. The metallization system mentioned above was used for initial testing at $300{ }^{\circ} \mathrm{C}$ without any complications.

\section{B. Device Characterization}

The DC characterization of the fabricated devices was performed using semiconductor characterization system by Keithley (SCS-4200). Fig. 2(a) shows the measured collector current $\left(\mathrm{I}_{\mathrm{C}}\right)$ and base current $\left(\mathrm{I}_{\mathrm{B}}\right)$ of a fabricated device as a function of base-emitter voltage $\left(V_{B E}\right)$ over a wide temperature range. The base-collector voltage $\left(V_{C B}\right)$ was kept

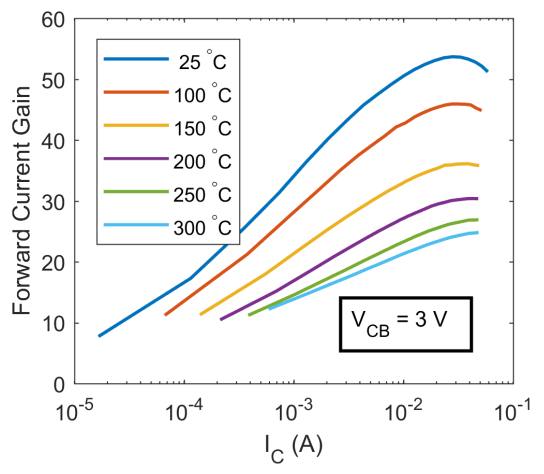

Fig. 3. Measured forward current gain versus $I_{C}$.

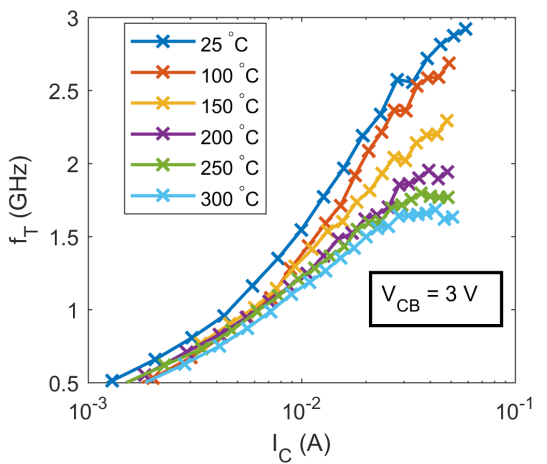

(a)

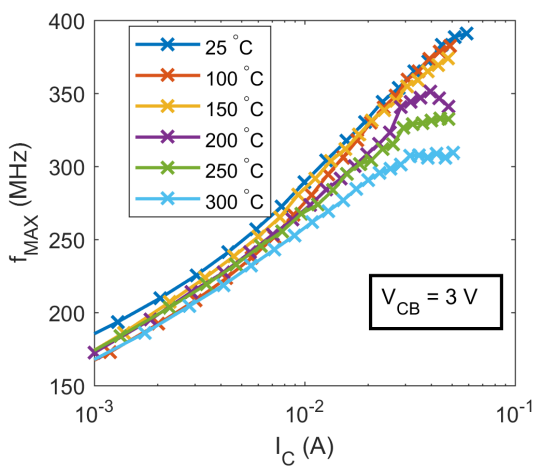

(b)

Fig. 4. Extracted values of (a) $f_{T}$ and (b) $f_{M A X}$ versus $\mathrm{I}_{\mathrm{C}}$.

constant at $3 \mathrm{~V}$ throughout the measurement. The output characteristics of the transistor at $\mathrm{I}_{\mathrm{B}}=200 \mu \mathrm{A}$ are shown in Fig. 2(b). Fig. 3 shows the measured forward current gain $(\beta)$ as a function of $\mathrm{I}_{\mathrm{C}}$. It can be seen that the maximum value of $\beta$ decreases with temperature from 54 at $25{ }^{\circ} \mathrm{C}$ to 24 at $300{ }^{\circ} \mathrm{C}$. The decrease in $\beta$ with temperature in SiC BJTs is related to the concentration of ionized dopants in the base region [16].

The S-parameters of the aforementioned device were measured to extract two important RF figures of merit i.e. unity current gain bandwidth $\left(f_{T}\right)$ and maximum oscillation frequency $\left(f_{M A X}\right)$. The S-parameters were measured with an Agilent vector network analyzer (8361A), using hightemperature RF probes (40A-GSG-150-DP-HT by PicoProbe) mounted on a manual probe station. Before measurements, 


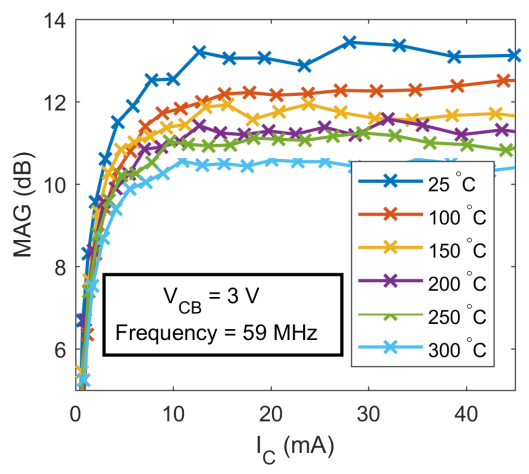

Fig. 5. Measured MAG at $59 \mathrm{MHz}$ versus $I_{C}$.

the vector network analyzer (VNA) was calibrated at room temperature using short/open/load/though (SOLT) standards on a calibration substrate by GGB Industries Inc. Fig. 4(a) and Fig. 4(b) show the extracted values of $f_{T}$ and $f_{M A X}$ as a function of $\mathrm{I}_{\mathrm{C}}$, respectively. As temperature increased from $25{ }^{\circ} \mathrm{C}$ to $300{ }^{\circ} \mathrm{C}$, the maximum values of $f_{T}$ and $f_{M A X}$ decreased by $42 \%$ and $23 \%$, respectively. The relatively low values of $f_{M A X}$ as compared to $f_{T}$ are attributed to the high base resistance of $\mathrm{SiC}$ BJTs [17].

\section{Amplifier Design}

The amplifier design considerations from the selection of optimum biasing, topology, issues pertaining to gain and noise of the amplifier as a function of matching to high-temperature prototyping are addressed in this section.

\section{A. Selection of Bias Point, Topology and Matching Network}

The amplifier is designed for an intermediate frequency of $59 \mathrm{MHz}$. The design frequency is selected as a trade-off, dictated at the high end by the power gain of the fabricated devices and at the low end by the practical limitations on the size of passives. Fig. 5 shows the maximum available power gain (MAG) versus $\mathrm{I}_{\mathrm{C}}$ plot of the BJT in commonemitter (CE) configuration, at the design frequency. Note that the MAG varies marginally above $10 \mathrm{~mA}$ at all the measured temperatures. Therefore, increasing $\mathrm{I}_{\mathrm{C}}$ above $10 \mathrm{~mA}$ would only increase the DC power consumption of the BJT without significantly improving its MAG. At $10 \mathrm{~mA}$, the MAG of a single BJT is $12 \mathrm{~dB}$ at room temperature, which degrades to around $10 \mathrm{~dB}$ at $300{ }^{\circ} \mathrm{C}$. To increase the gain of the amplifier, a cascade of two BJTs in CE configuration, each biased at $10 \mathrm{~mA}$, was selected. With lossless conjugate matching, a two-stage topology comprised of identical gain stages can theoretically provide twice as much gain (in $\mathrm{dBs}$ ) as a single stage. Conjugate matching, however, does not generally provide the best noise performance. To analyze this trade-off between gain and noise, the total noise figure $\left(N F_{t o t}\right)$ of a two-stage amplifier made up of identical transistor stages is considered [18]:

$$
N F_{t o t}=10 \log _{10}\left(10^{(N F / 10)}+\frac{10^{(N F / 10)}-1}{A_{p}}\right)
$$

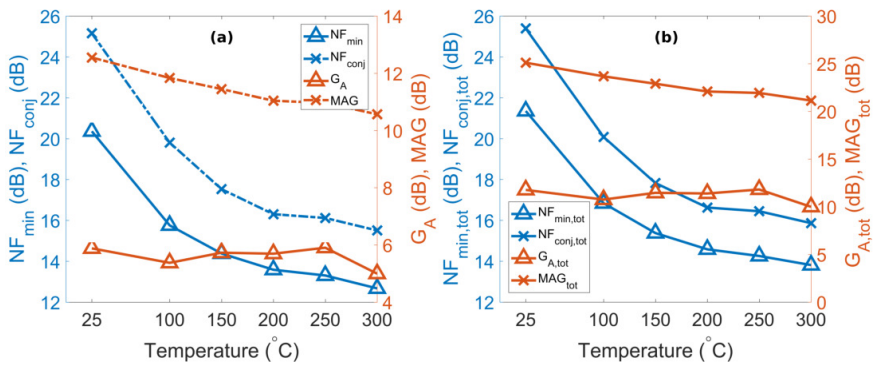

Fig. 6. Calculated values of (a) $N F_{\min }, N F_{\text {conj }}, G_{A}$ and MAG of a single SiC BJT (b) $N F_{\text {min,tot }}, N F_{\text {conj,tot }}, G_{A, t o t}$ and $\mathrm{MAG}_{t o t}$ of two cascaded SiC BJTs. $\mathrm{I}_{\mathrm{C}}=10 \mathrm{~mA}$ and frequency $=59 \mathrm{MHz}$.

where $N F$ is the noise figure and $A_{p}$ is the power gain of a single transistor stage. $N F$ in (1) can be calculated by [19]:

$$
N F=10 \log _{10}\left(F_{\text {min }}+\frac{R_{n}}{G_{G}}\left|Y_{G}-Y_{\text {opt }}\right|^{2}\right)
$$

where $Y_{G}=G_{G}+j B_{G}$ is the source admittance driving each stage, $F_{\min }$ is the minimum noise factor, $R_{n}$ is the noise resistance and $Y_{\text {opt }}$ is the source admittance at minimum noise factor. $Y_{G}$ was assumed to be $(1 / 50) \Omega^{-1}$ for both stages. The noise parameters of the transistor (i.e. $F_{\min }, R_{n}$ and $Y_{o p t}$ ) can be calculated from the so-called thermodynamical model [20], [21]. The noise figure of each stage can be minimized by transforming its source admittance $Y_{G}$ to $Y_{\text {opt }}$, thereby making the second term in (2) zero. This transformation can be done by using appropriate input matching networks. However, this transformation leads to a gain, called associated gain $\left(G_{A}\right)$, which is generally smaller than the MAG as shown in Fig. 6(a) for a single transistor. Fig. 6(a) also shows the improvement in the noise figure corresponding to the noise matching $\left(N F_{\min }\right)$ over its conjugate matching $\left(N F_{c o n j}\right)$ counterpart. Note that irrespective of the type of matching, noise figure decreases with temperature. This decrease in noise figure with temperature is related to the corresponding decrease in the thermal resistances of $\mathrm{SiC}$ BJTs with temperature [17]. The variation of gain in the first stage also affects $N F_{t o t}$ through $A_{p}$, whose value is equal to MAG for conjugate matching and $G_{A}$ for noise matching. Fig. 6(b) shows the total minimum noise figure $\left(N F_{m i n, t o t}\right)$ and the total associate gain $\left(G_{A, t o t}\right)$ of the two-stage amplifier when input matching networks of both stages are optimized for noise performance. It also shows the noise figure $\left(N F_{c o n j, t o t}\right)$ and the total maximum available gain $\left(\mathrm{MAG}_{t o t}\right)$ when both stages are conjugately matched. It can be seen that by selecting conjugate matching over noise matching, the gain increases by around $118 \%$ whereas noise performance deteriorates by only $15 \%$. This result, combined with the fact that noise is not a critical parameter in IF amplifiers, has motivated the selection of conjugate matching networks for both stages.

\section{B. Circuit Design}

The amplifier circuit was designed and simulated using the S-parameters of the BJT which was the subject of discussion in Section II.B and Section III.A. However, the actual amplifier implementation was done using two other BJTs, which were identical to the measured one and located on the same die. This 


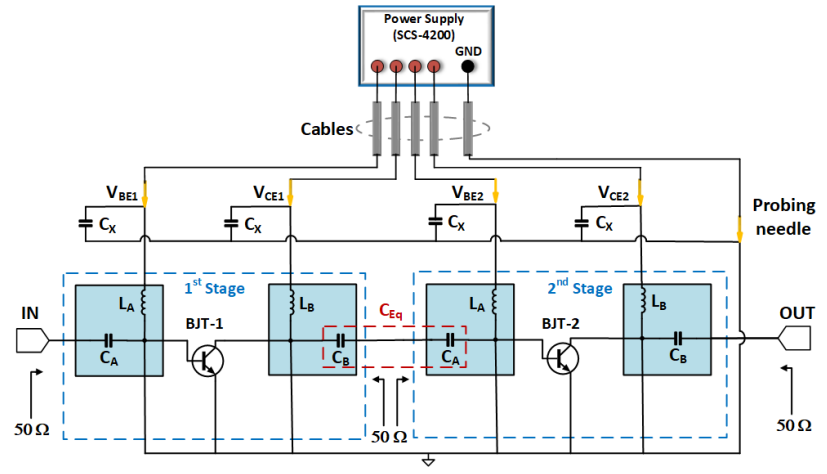

Fig. 7. Circuit diagram of the proposed IF amplifier.

was done primarily because S-parameters of the BJTs used for implementing the amplifier could not be measured as they were fabricated with DC pads. Nevertheless, it is reasonable to assume that due to the close proximity of the BJTs used for design and implementation, their S-parameter dispersion remains low. This assumption was also verified by comparing the measured S-parameters of two identical BJTs located on adjacent dies.

The matching networks of the proposed IF amplifier were designed in ADS by Keysight Technologies using the measured S-parameters. The circuit diagram of the amplifier is shown in Fig. 7. The $50 \Omega$ conjugate matching is realized with four highlighted $\mathrm{L}$-section networks using lumped capacitors $\mathrm{C}_{A}=6 \mathrm{pF}, \mathrm{C}_{B}=27 \mathrm{pF}$ and inductors $\mathrm{L}_{A}=1050 \mathrm{nH}$, $\mathrm{L}_{B}=202 \mathrm{nH}$. The two interstage capacitors are replaced by a single equivalent capacitor $\mathrm{C}_{E q}=4.9 \mathrm{pF}$. $\mathrm{V}_{\mathrm{BEx}}$ and $\mathrm{V}_{\mathrm{CEx}}$ represent the biasing base-emitter and collector-emitter voltages, respectively ( $\mathrm{x}$ is 1 for the first stage and 2 for the second stage). The biasing voltages and the DC ground from the power supply are brought to the circuit using approximately 1.5 meter long cables in conjunction with the DC probing needles (which are not drawn to scale). The selected configuration for the L-sections eliminates the need for additional bias-tees i.e. DC block capacitors and RF chokes. Both $L_{A}$ and $\mathrm{L}_{B}$, in addition to matching, also act as low resistance paths for the DC signals. Similarly, matching capacitors $\mathrm{C}_{A}, \mathrm{C}_{B}$ and $\mathrm{C}_{E q}$ also function as DC blocks. This reduces the number of passive components and circuit complexity which, in turn, improves the circuit reliability at high temperatures. The four bypass capacitors, $\mathrm{C}_{\mathrm{x}}=5.6 \mathrm{nF}$, provide a low impedance path to the $\mathrm{AC}$ signals in comparison to the largely inductive path to the power supply via cables and probing needles, thereby preventing signal leakage. The circuit does not require any stabilization network as all the measured devices are unconditionally stable at the measured biasing conditions, frequency ranges and temperatures.

Rogers-4003C printed circuit board (PCB) was selected for the amplifier implementation. The selected PCB uses a hightemperature substrate which has a glass transition temperature of around $280{ }^{\circ} \mathrm{C}$. The matching network inductors were realized with on-PCB spirals which, in turn, were designed in the EM simulator of ADS. The spacing between the inductor coils and the width of the coils were kept at $0.3 \mathrm{~mm}$ for

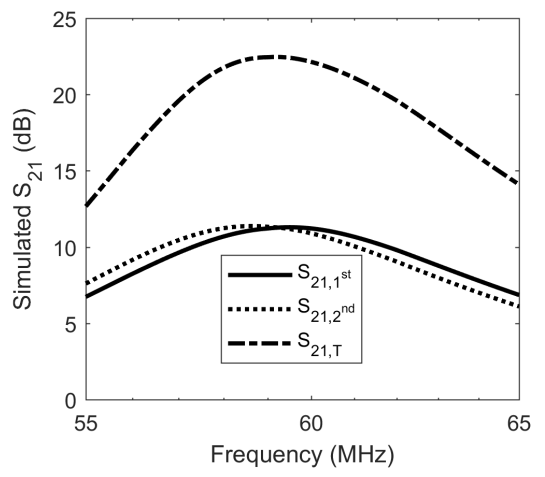

Fig. 8. Simulated gain of the $1^{\text {st }}$ stage, $2^{\text {nd }}$ stage and the total gain of the proposed amplifier at room temperature.

all the inductors. To minimize the area consumption, $\mathrm{L}_{A}$ $(=1050 \mathrm{nH})$ was realized by stacking two spiral inductors, one on top and the other on the bottom metal layer of the PCB. For $\mathrm{L}_{B}(=202 \mathrm{nH})$, a single spiral inductor on the top metal layer was used while the crossover was done in the bottom metal layer. The area occupied by $\mathrm{L}_{A}$ and $\mathrm{L}_{B}$ was $130 \mathrm{~mm}^{2}$ and $75 \mathrm{~mm}^{2}$, respectively. Fig. 8 shows the gains from the post-layout EM simulation of the amplifier at room temperature. $S_{21,1^{\mathrm{st}}}, S_{21,2^{\text {nd }}}$ and $S_{21, T}$ represent the gain of the first stage, second stage and total gain of the two stages, respectively. Though the simulations were performed using the same set of S-parameters for both stages, one can see a slight shift in the center frequency in $S_{21,1^{\text {st }}}$ and $S_{21,2^{\text {nd }}}$ due to the asymmetricity in the layouts of two stages. Since the simulated center frequency offset between the two stages is relatively small, $S_{21, T}$ roughly appears as a scaled version of a single amplifier stage. However, due to the parameter dispersion between the transistors and/or matching networks of multistage amplifiers, the offset in center frequency generally manifests as distinct peaks in the overall measured gain or a trapezoidal shaped gain profile depending on the quality factor of the circuit. As it will be shown in the next section, the profile of the measured gain is slightly more trapezoidal than the profile of $S_{21, T}$.

The IF amplifier was prototyped on a two-layer Rogers4003C PCB with $35 \mu \mathrm{m}$ copper metallization and electroless nickel/immersion gold (ENIG) surface finish. NP0 capacitors by Presidio Components Inc., which are rated up to $250{ }^{\circ} \mathrm{C}$, were used for matching and bypassing purposes. These were the highest temperature rated capacitors available commercially at the time of selection. Indalloy-151 material (melting point of $301{ }^{\circ} \mathrm{C}$ ) was selected to solder the aforementioned capacitors to the PCB pads. The chip with the SiC BJTs was diced from the wafer and attached directly to the PCB using a high-temperature alumina adhesive (Resbond 989F) by ChemTech AB. The on-chip BJTs and the PCB traces were connected by $25 \mu m$ thick gold bond wires.

\section{Measurement Results and Discussion}

\section{A. Measurement Setup}

The prototype of the IF amplifier, including the chip containing the BJT used in characterization and designing 


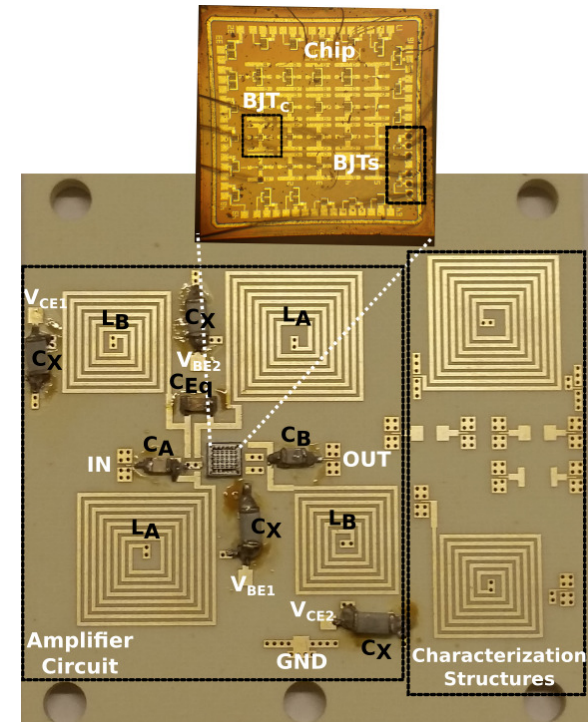

Fig. 9. Prototype of the IF amplifier including the chip with SiC BJTs.

phase (marked as $\mathrm{BJT}_{\mathrm{C}}$ ), the two BJTs used for amplifier implementation and their bond wire connections are shown in Fig. 9. The PCB occupies a total area of $49 \times 46 \mathrm{~mm}^{2}$. To provide electrical isolation between the bottom metal of the PCB and the test fixture, a dummy Rogers-4003C PCB (without top metallization) of identical dimensions was glued beneath the original PCB using Resbond 989F. For hightemperature measurements, the circuit was placed on a thermal metallic chuck and the temperature of the chuck $\left(T_{c h k}\right)$ was increased in steps from $25{ }^{\circ} \mathrm{C}$ up to $300{ }^{\circ} \mathrm{C}$. At each value of $T_{c h k}$, average equilibrium temperature at the top surface of the PCB $\left(T_{t o p}\right)$ was measured with an IR thermometer. Though both the $T_{c h k}$ and the corresponding $T_{t o p}$ values are mentioned in this section, the final results of this work report only $T_{t o p}$.

\section{B. Measurement Results}

The amplifier prototype was biased with SCS-4200 using high-temperature probing needles and its S-parameters were measured with Rohde \& Schwarz VNA (ZVC series). VNA source power of $-25 \mathrm{dBm}$ was used for the S-parameter measurements. One meter long coaxial cables in conjunction with high-temperature RF probes were used to connect the VNA ports to the on-PCB Ground-Signal-Ground (GSG) $I N$ and $O U T$ pads of the amplifier. Throughout the temperature range, $\mathrm{I}_{\mathrm{C}}$ and $V_{C B}$ of both amplifier stages were kept at 10 $\mathrm{mA}$ and $3 \mathrm{~V}$, respectively.

The measured S-parameters of the IF amplifier are shown in Fig. 10. To distinguish between $T_{c h k}$ and $T_{t o p}$, the legend entries follow the syntax: $T_{c h k}$ (corresponding $T_{t o p}$ ). Note that the center frequency has shifted down to around $54.6 \mathrm{MHz}$ as compared to its design value of $59 \mathrm{MHz}$. This frequency deviation can be attributed to the equivalent inductances of $L_{A}$ and $L_{B}$ being different than their simulated values, tolerances in the matching capacitor values and/or parameter variation of the active devices used for implementing the amplifier as compared to the one used for simulation. The contribution of the first factor to the frequency shift will be discussed shortly.

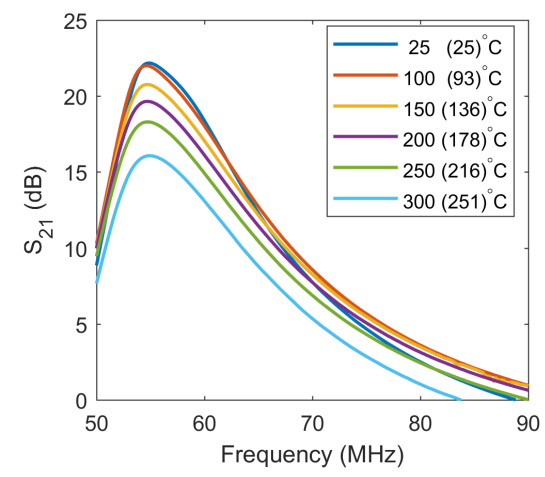

(a)

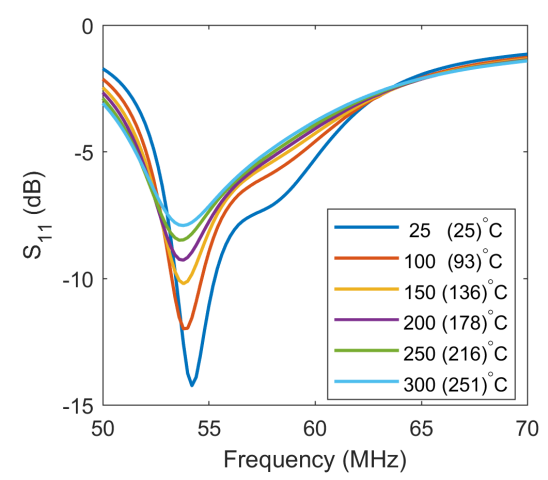

(b)

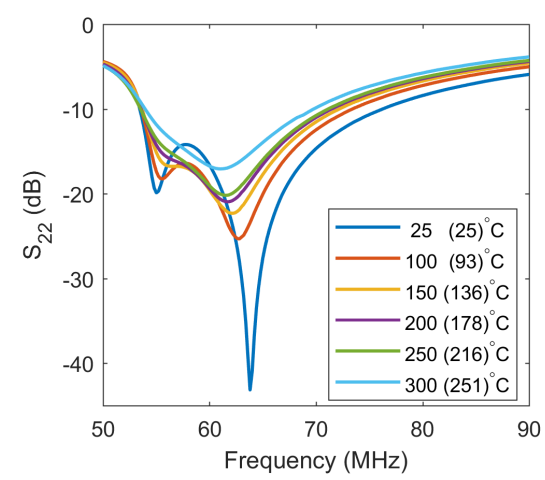

(c)

Fig. 10. Measured (a) gain, (b) input return loss and (c) output return loss of the IF amplifier at temperatures $T_{c h k}$ (corresponding $T_{t o p}$ ).

The measured gain $\left(S_{21}\right)$ of the IF amplifier is shown in Fig. 10(a). The maximum measured gain decreases gradually with temperature from $22 \mathrm{~dB}$ at $T_{t o p}=25{ }^{\circ} \mathrm{C}$ to $16 \mathrm{~dB}$ at $T_{\text {top }}=$ $251{ }^{\circ} \mathrm{C}$. The gain degradation with temperature is attributed to the decrease in the intrinsic gain of the BJTs (refer to Fig. 5) as well as due to the losses in the passives of the matching networks and the mismatch losses. The latter effect can be seen in Fig. 10(b) and Fig. 10(c) which shows the input matching $\left(S_{11}\right)$ and the output matching $\left(S_{22}\right)$ of the amplifier, respectively. Although around the center frequency both $S_{11}$ and $S_{22}$ degrade with temperature, the amplifier still maintains a reasonable match $\left(S_{11}<-7 \mathrm{~dB}, S_{22}<-11 \mathrm{~dB}\right)$ at $54.6 \mathrm{MHz}$, throughout the entire temperature range.

A single-tone test was carried out to evaluate the linearity of the amplifier. The input of the amplifier was fed with a 

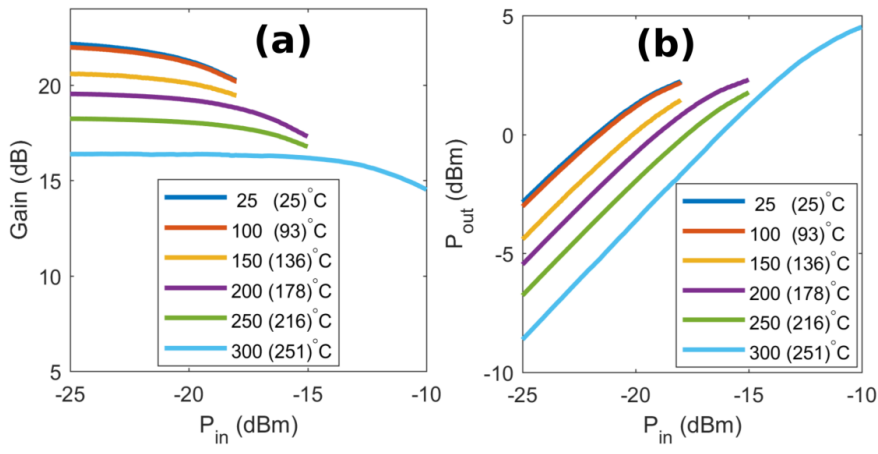

Fig. 11. Measured (a) gain and (b) output power of the amplifier as a function of the input power at $54.6 \mathrm{MHz}$.

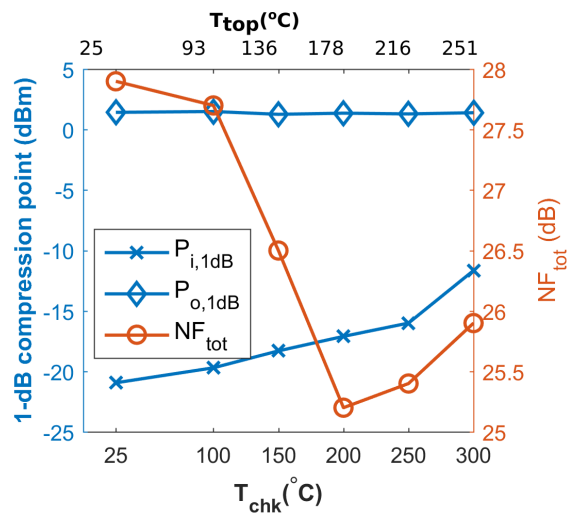

Fig. 12. Measured 1-dB compression points and noise figure of the amplifier.

54.6 MHz signal and the power of the input signal $\left(\mathrm{P}_{\mathrm{in}}\right)$ was swept. The measured gain and output power $\left(\mathrm{P}_{\text {out }}\right)$ of the amplifier as a function of $P_{\text {in }}$ is shown in Fig. 11(a) and Fig. 11(b), respectively. These plots were used to extract the 1-dB input $\left(P_{i, 1 d B}\right)$ and output $\left(P_{o, 1 d B}\right)$ compression points which are shown in Fig. 12. It can be seen that $P_{i, 1 d B}$ improves from $-21 \mathrm{dBm}$ at $25{ }^{\circ} \mathrm{C}$ to $-12 \mathrm{dBm}$ at $251^{\circ} \mathrm{C}$. However, this apparent improvement in the linearity of the amplifier with temperature is caused by the corresponding gain degradation. This can be seen from $P_{o, 1 d B}$, which remains fairly constant with temperature around $1.4 \mathrm{dBm}$. The noise figure of the amplifier was measured at $54.6 \mathrm{MHz}$ using the gain method [22]. In the gain method, noise figure is calculated from the measured noise floor of the amplifier output $\left(\mathrm{P}_{\text {Nout }}\right)$ and its gain by using the relationship:

$$
N F_{\text {tot }}=\kappa T+\mathrm{P}_{\text {Nout }}-S_{21}
$$

where $\kappa$ is the Boltzmann's constant and $T$ is the temperature. In (3), $\kappa T$ and $\mathrm{P}_{\text {Nout }}$ are expressed in $\mathrm{dBm} / \mathrm{Hz}$ whereas $S_{21}$ and $N F_{\text {tot }}$ are represented in $\mathrm{dBs}$. $\mathrm{P}_{\text {Nout }}$ was measured using Rohde \& Schwarz spectrum analyzer (FSQ-26) and the measured noise figure is shown in Fig. 12. At room temperature, the measured noise figure is $27.8 \mathrm{~dB}$ which is reasonably close to the simulated value of $25.7 \mathrm{~dB}$ shown in Fig. 6(b). Though not as pronounced as predicted in Fig. 6(b), the measured noise figure also decreases up to $T_{t o p}=178{ }^{\circ} \mathrm{C}$.
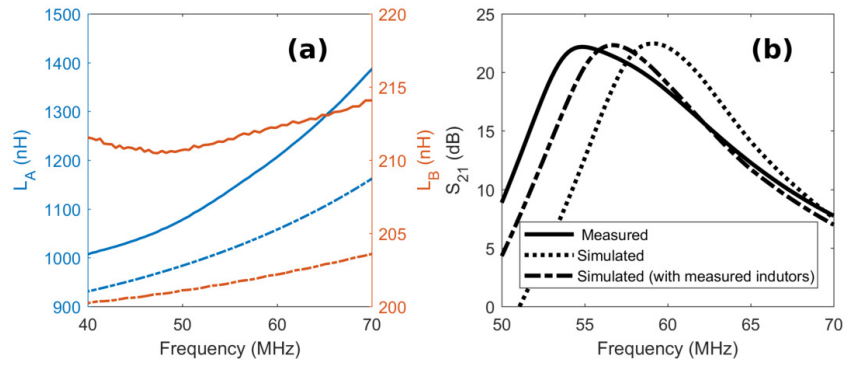

Fig. 13. (a) Room temperature values of $\mathrm{L}_{A}$ and $\mathrm{L}_{B}$. Measured (solid) and simulated (dashed). (b) Gain of the amplifier at room temperature.

TABLE I

SUMMARIZED MEASUREMENT RESULTS FOR THE IF AMPLIFIER AT $54.6 \mathrm{MHz}$

\begin{tabular}{cccccc}
\hline \hline $\begin{array}{c}T_{\text {chk }} / T_{\text {top }} \\
\left({ }^{\circ} \mathrm{C}\right)\end{array}$ & $\begin{array}{c}S_{21} \\
(\mathrm{~dB})\end{array}$ & $\begin{array}{c}S_{11} / S_{22} \\
(\mathrm{~dB})\end{array}$ & $\begin{array}{c}N F \\
(\mathrm{~dB})\end{array}$ & $\begin{array}{c}P_{i, 1 d B} / P_{o, 1 d B} \\
(\mathrm{dBm})\end{array}$ & $\begin{array}{c}\text { Power } \\
(\mathrm{mW})\end{array}$ \\
\hline $25 / 25$ & 22 & $-13 /-18$ & 27.8 & $-20.94 / 1.43$ & 217 \\
$100 / 93$ & 22 & $-10 /-15.5$ & 27.6 & $-19.7 / 1.5$ & 214 \\
$150 / 136$ & 20.8 & $-9 /-13.7$ & 26.5 & $-18.3 / 1.3$ & 221 \\
$200 / 178$ & 19.6 & $-8 /-13.2$ & 25 & $-17.1 / 1.4$ & 209 \\
$250 / 216$ & 18.3 & $-7.8 /-12.7$ & 25.4 & $-16 / 1.3$ & 214 \\
$300 / 251$ & 16 & $-7.5 /-11.2$ & 25.9 & $-11.6 / 1.4$ & 198 \\
\hline \hline
\end{tabular}

One potential reason for the difference between the measured and the simulated noise figures can be the degradation of the input matching with temperature. For $T_{t o p}>178{ }^{\circ} \mathrm{C}$, $N F_{\text {tot }}$ increases with temperature as the gain of the first stage decreases and therefore, can not effectively suppress the noise of the second stage.

In Fig. 13(a), the effective inductances of both $\mathrm{L}_{A}$ and $\mathrm{L}_{B}$ at room temperature are shown. The measurements were performed on the characterization inductors shown in Fig. 9. Note that the measured effective inductances of $L_{A}$ and $L_{B}$ are larger than their corresponding simulated values. To evaluate the effect of increased inductances on the frequency shift of the amplifier, we replaced the EM simulated inductors in ADS with their measured counterparts, followed by resimulating the amplifier circuit. The simulated gain of the amplifier at room temperature, using the measured inductors, is shown in Fig. 13(b). It can be seen that the simulated gain is now centered around $56.3 \mathrm{MHz}$, implying that the increased effective inductances resulted in a $4.6 \%$ decrease in the center frequency from its nominal value of $59 \mathrm{MHz}$. Though, it is generally possible to tune the center frequency e.g. by adjusting the values of matching network capacitors, no tuning was performed in this work. Lastly, it can also be seen that the profile of the measured gain is slightly more trapezoidal as compared to the the profile of the simulated gain due to the parameter dispersion between the two stages. The summary of the measurement results is given in Table. I.

The three set of measurements for the amplifier characterization i.e. gain and matching, linearity and noise were conducted in separate thermal cycles. Same set of measurements were also performed at $\mathrm{I}_{\mathrm{C}}=20 \mathrm{~mA}$ and $30 \mathrm{~mA}$ (not reported for the sake of brevity) for a total of nine temperature 
cycles. We observed negligible performance degradation due to thermal cycling despite the strong coloration of the PCB after high-temperature exposure. Furthermore, we also did not observe any structural failure in the dummy Rogers-4003C PCB which was exposed to $300{ }^{\circ} \mathrm{C}$, a value slightly higher than its vendor's specified glass transition temperature of $280{ }^{\circ} \mathrm{C}$.

\section{CONCLUSION}

A high-temperature IF amplifier has been presented in this paper. The amplifier employs a two-stage cascaded topology and each stage is composed of an in-house SiC BJT in a common-emitter configuration. Measurement results have shown that the proposed amplifier operates reliably up to $251{ }^{\circ} \mathrm{C}$, the limiting temperature of our RF measurement setup. At $251{ }^{\circ} \mathrm{C}$ and $54.6 \mathrm{MHz}$ frequency, it achieves a gain, input and output matching of $16 \mathrm{~dB},-7.5 \mathrm{~dB}$ and $-11.2 \mathrm{~dB}$, respectively. The output $1-\mathrm{dB}$ compression point of the amplifier remains fairly constant with temperature around $1.4 \mathrm{dBm}$. The amplifier has a maximum power dissipation of $221 \mathrm{~mW}$. The measured performance of the IF amplifier demonstrates its feasibility as a small signal gain block for high-temperature communication receivers.

\section{ACKNOWLEDGMENT}

The authors would like to thank Knut and Alice Wallenberg foundation for funding this work.

\section{REFERENCES}

[1] L. Stoica, S. Riches, and C. Johnston, High Temperature Electronics Design for Aero Engine Controls and Health Monitoring. River Publishers, 2016.

[2] J. D. Cressler and H. A. Mantooth, Extreme Environment Electronics. CRC Press, 2012.

[3] National Research Council, Vision and Voyages for Planetary Science in the Decade 2013-2022. The National Academic Press, 2011.

[4] M. A. Huque, L. M. Tolbert, B. J. Blalock, and S. K. Islam, "Siliconon-insulator-based high-voltage, high-temperature integrated circuit gate driver for silicon carbide-based power field effect transistors," IET Power Electron., vol. 3, no. 6, pp. 1001-1009, Nov 2010. doi: 10.1049/ietpel.2008.0287.

[5] P. G. Neudeck, R. S. Okojie, and L.-Y. Chen, "High-temperature electronics - A role for wide bandgap semiconductors?" Proc. IEEE, vol. 90, no. 6, pp. 1065-1076, Jun 2002. doi: 10.1109/JPROC.2002.1021571.

[6] V. Carrubba, S. Maroldt, M. Musser, E. Ture, M. Dammann, F. van Raay, R. Quay, P. Brckner, and O. Ambacher, "High-efficiency, hightemperature continuous class-E sub-waveform solution AlGaN/GaN power amplifier," IEEE Microw. Wireless Compon. Lett., vol. 25, no. 8, pp. 526-528, Aug 2015. doi: 10.1109/LMWC.2015.2440758.

[7] P. Waltereit, J. Khn, R. Quay, F. van Raay, M. Dammann, M. Csar, S. Mller, M. Mikulla, O. Ambacher, J. Ltti, M. Rostewitz, K. Hirche, and J. Dubler, "High efficiency X-band AlGaN/GaN MMICs for space applications with lifetimes above 105 hours," in Proc. 7th Eur. Microw. Integr. Circuits Conf., Oct 2012, pp. 123-126.

[8] M. L. Cunningham, D. S. Ha, and K. J. Koh, "A high temperature wideband low noise amplifier for downhole applications," in Proc. Int. Symp. Circuits Syst., May 2016. doi: 10.1109/ISCAS.2016.7527396. pp. 938-941.

[9] M. Ehteshamuddin, J. M. Salem, and D. S. Ha, "A high temperature variable gain amplifier based on GaN HEMT devices for downhole communications," in Proc. Int. Symp. Circuits Syst., May 2017. doi: 10.1109/ISCAS.2017.8050376. pp. 1-4.

[10] L. Lanni, B. G. Malm, M. Östling, and C. M. Zetterling, "500 ${ }^{\circ} \mathrm{C}$ Bipolar Integrated OR/NOR Gate in 4H-SiC," IEEE Electron Device Lett., vol. 34, no. 9, pp. 1091-1093, Sept 2013. doi: 10.1109/LED.2013.2272649.
[11] H. Elahipanah, A. Salemi, C.-M. Zetterling, and M. Östling, "5.8$\mathrm{kV}$ implantation-free $4 \mathrm{H}-\mathrm{SiC}$ BJT with multiple-shallow-trench junction termination extension," IEEE Electron Device Lett., vol. 36, no. 2, pp. 168-170, 2015. doi: 10.1109/LED.2014.2386317.

[12] H. Elahipanah, A. Salemi, C. M. Zetterling, and M. Östling, "4.5-kV 20-m $\Omega . \mathrm{cm}^{2}$ implantation-free $4 \mathrm{H}-\mathrm{SiC}$ BJT with trench structures on the junction termination extension," Mater. Sci. Forum, vol. 821, pp. 838-841, 2015. doi: 10.4028/www.scientific.net/MSF.821-823.838.

[13] L. Lanni, B. G. Malm, M. Östling, and C.-M. Zetterling, "Influence of passivation oxide thickness and device layout on the current gain of $\mathrm{SiC}$ BJTs," IEEE Electron Device Lett., vol. 36, no. 1, pp. 11-13, 2015. doi: 10.1109/LED.2014.2372036.

[14] R. S. Okojie, D. Lukco, Y. L. Chen, and D. J. Spry, "Reliability assessment of $\mathrm{Ti} / \mathrm{TaSi}_{2} / \mathrm{Pt}$ ohmic contacts on $\mathrm{SiC}$ after $1000 \mathrm{~h}$ at $600{ }^{\circ}$ C, Journal of Applied Physics, vol. 91, no. 10, pp. 6553-6559, 2002. doi: $10.1063 / 1.1470255$.

[15] S. Tanimoto and $\mathrm{H}$. Oohashi, "High-temperature reliable $\mathrm{Ni}_{2} \mathrm{Si}$ based contacts on $\mathrm{SiC}$ connected to $\mathrm{Si}$-doped $\mathrm{Al}$ interconnect via Ta/TaN Barrier," Mater. Sci. Forum, vol. 615, pp. 561-564, 2009. doi: 10.4028/www.scientific.net/MSF.615-617.561.

[16] P. A. Ivanov, M. E. Levinshtein, A. K. Agarwal, S. Krishnaswami, and J. W. Palmour, "Temperature dependence of the current gain in power 4H-SiC NPN BJTs," IEEE Trans. Electron Devices, vol. 53, no. 5, pp. 1245-1249, May 2006. doi: 10.1109/TED.2006.872701.

[17] L. Lanni, R. Ghandi, B. G. Malm, C. M. Zetterling, and M. Ostling, "Design and characterization of high-temperature ECL-based bipolar integrated circuits in 4H-SiC," IEEE Trans. Electron Devices, vol. 59, no. 4, pp. 1076-1083, April 2012. doi: 10.1109/TED.2011.2182514.

[18] H. T. Friis, "Noise figures of radio receivers," in Proc. of IRE, vol. 32, no. 7, 1944, pp. 419-422.

[19] A. van der Ziel, "Representation of noise in linear two-ports," Proc. IEEE, vol. 57, no. 6, pp. 1211-1211, June 1969. doi: 10.1109/PROC.1969.7203.

[20] U. Zillmann and F. Herzel, "An improved SPICE model for highfrequency noise of BJTs and HBTs," IEEE J. Solid-State Circuits, vol. 31, no. 9, pp. 1344-1346, Sep 1996. doi: 10.1109/4.535422.

[21] F. Herzel, P. Schley, B. Heinemann, U. Zillmann, D. Knoll, D. Temmler, and U. Erben., "Experimental verification and numerical application of the thermodynamic approach to high-frequency noise in SiGe HBTs," Solid-State Electron., vol. 41, no. 3, pp. 387 - 390, 1997. doi: 10.1016/S0038-1101(96)00178-5.

[22] "High-Accuracy Noise Figure Measurements using the PNA-X Series Network Analyzer," Keysight Technologies, Inc., Appl. Note 59905800 EN.

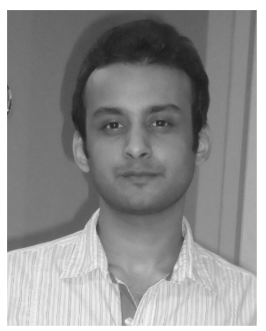

Muhammad Waqar received the M.Sc. degree in system-on-chip design from the KTH Royal Institute of Technology, Stockholm, Sweden, in 2012. Currently, he is working towards his Ph.D. degree in the Department of Integrated Devices and Circuits in the ICT School at KTH. His research interests include AC characterization and RF design of high temperature bipolar integrated devices and circuits.

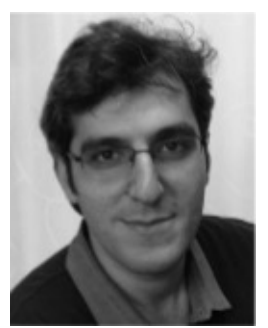

Hossein Elahipanah (M'10) is with the company Ascatron AB, Stockholm, Sweden, as design engineer. $\mathrm{He}$ is working on $\mathrm{SiC}$-based high power devices and high temperature integrated circuits for next generation of power electronics. 


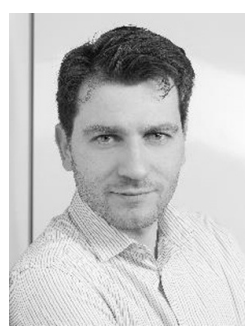

Stephan Schröder studied Microsystem technology at the HTW in Berlin, Germany and received his Diploma in 2010. Since 2011, he is conducting his Ph.D. studies at the Department of Micro and Nanosystems at KTH Royal Institute of Technology, Stockholm, Sweden. Stephan focuses on unconventional approaches of wire bonding technology for gas sensing applications and 3D packaging application of MEMS devices.

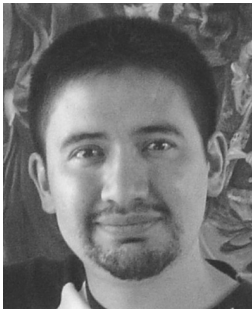

environments.

Saul (M'06) received the B.Sc. degree in Electrical Engineering from the Army Polytechnic School (ESPE), Quito, Ecuador in 2001, the M.Sc. degree in System-on-Chip Design in 2005 and the Ph.D. degree in Electronic and Computer Systems in 2009 from the Royal Institute of Technology (KTH), Stockholm, Sweden. His research area covers from RF CMOS circuit design for wideband front-ends, ultra-low power circuits for medical applications, and emerging technologies such as graphene based electronics and $\mathrm{SiC}$ circuits for high temperature

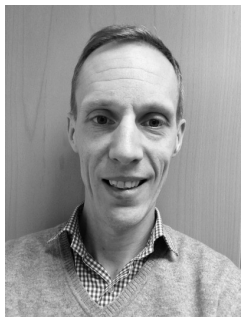

Bengt Gunnar Malm (M'98-SM'10) was born in Stockholm, Sweden, in 1972. He received the M.S. from Uppsala University, Sweden, in 1997, the PhD in solid-state electronics 2002, from Royal Institute of Technology (KTH),Stockholm. He is an Associate Professor at the School of ICT, KTH since 2011. His recent work includes silicon carbide technology for extreme environments and spintronics for microwave and logic applications.

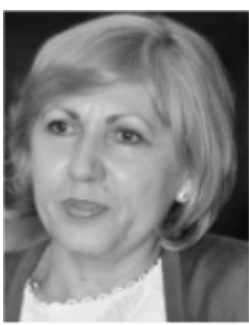

Ana Rusu (M'92) received the M.Sc. degree in electronics and telecommunications from the Technical University of Iaşi, Iaşi, Romania, in 1983, and the Ph.D. degree from the Technical University of Cluj-Napoca, Cluj-Napoca, Romania, in 1998. She has been with the KTH Royal Institute of Technology, Stockholm, Sweden, since 2001, where she is currently a Professor of Electronic Circuits for Integrated Systems.

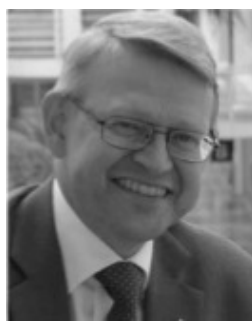

Mikael Östling (M'85-SM'97-F'04) received the Ph.D. degree from Uppsala University, Uppsala, Sweden, in 1983. He is currently a Professor and the Deputy President with the KTH Royal Institute of Technology, Stockholm, Sweden. His current research interests include silicon/silicon germanium devices and process technology for very high frequency, and device technology for wide bandgap semiconductors with special emphasis on silicon carbide for high-power applications 